\title{
Práticas do olhar, transformações do torcer: alianças e rivalidades na luta corporal Alto- Xinguana
}

Practices of looking, transformations in cheering: alliances and rivalries in

Upper Xingu wrestling

\section{Carlos Eduardo Costa}

\section{(2) OpenEdition Journals}

\section{Edição electrónica}

URL: https://journals.openedition.org/aa/8339

DOI: $10.4000 /$ aa. 8339

ISSN: 2357-738X

\section{Editora}

Programa de Pós-Graduação em Antropologia Social (UnB)

\section{Edição impressa}

Paginação: 237-253

ISSN: 0102-4302

\section{Refêrencia eletrónica}

Carlos Eduardo Costa, «Práticas do olhar, transformações do torcer: alianças e rivalidades na luta corporal Alto-Xinguana», Anuário Antropológico [Online], v.46 n.2 | 2021, posto online no dia 30 maio 2021, consultado o 01 junho 2021. URL: http://journals.openedition.org/aa/8339 ; DOI: https://doi.org/ 10.4000/aa.8339

\section{(c) (i) (9)}

Anuário Antropológico is licensed under a Creative Commons Atribuição-Uso Não-Comercial-Proibição de realização de Obras Derivadas 4.0 International. 


\title{
anuário antropológico \\ $v \cdot 46 \cdot n^{\circ} 2 \cdot$ maio-agosto $\cdot 2 \odot 21.2$
}

\section{Práticas do olhar, transformações do torcer: alianças e rivalidades na luta corporal Alto- Xinguana ${ }^{1}$}

\author{
Practices of looking, transformations in cheering: alliances and rivalries in Upper \\ Xinguan wrestling \\ DOI: https://doi.org/10.4000/aa.8339
}

\author{
Carlos Eduardo Costa \\ Universidade Federal de São Carlos, Programa de Pós-Graduação em Antropologia \\ Social, São Carlos, SP, Brasil \\ Doutor pelo Programa de Pós-graduação em Antropologia Social da UFSCar. Membro fundador do Labora- \\ tório de Estudos das Práticas Lúdicas e Sociabilidade (LELuS/UFSCar) e colaborador do site Ludopédio.
}

A luta corporal kindene é uma das práticas mais observadas no Alto Xingu, sendo registrada desde as pioneiras expedições no século XIX e por pesquisadores que trabalharam na demarcação da terra indígena em meados do século XX. Até mais recentemente, com a ampliação etnográfica dos povos e temas abordados, a kindene sempre foi alvo de sucintas, porém, prestigiosas descrições. Apesar desse caráter de epifenômeno, em meio a toda suntuosidade ritual na qual é primordialmente disputada, apresenta contendas políticas envolvendo a chefia; rivalidades históricas que atravessam gerações; transformações que consolidam sistemas regionais; emoções e performances entre lutadores e torcedores. A dinâmica da organização ritual, especialmente do egitsü, cerimônia pós-fúnebre em homenagem aos chefes, embaralha as relações interétnicas. Tais configurações promovem alianças e oposições na formação dos times e, por consequência, das torcidas que se rearranjam a cada evento. Este artigo propõe-se a dar maior visibilidade às relações entre os planos do jogar e do torcer, mediados pela faculdade do olhar nas comemorações das vitórias, indicando as transformações desencadeadas no universo relacional entre os povos da região. Posições determinantes para os combates rituais, os nginiko ("olhadores"), trazem à tona novos ângulos para tratarmos a complexidade das relações no contexto da chamada pax xinguana.

Alto Xingu. Luta ritual. Relações interétnicas. Olhar/jogar/torcer.
Kindene wrestling is one of the most frequently recorded practices in the Upper Xingu, from the pioneering expeditions of the 19th century to researchers who worked toward the demarcation of the Indigenous Land in the mid-20th century. Even with the recent demographic increase of peoples and the diversification of ethnographic themes addressed, the kindene remains the subject of succinct, if acute, descriptions. Despite this epiphenomenal character, in the midst all the ritual sumptuousness in which it is primarily disputed wrestling mobilizes political strife involving the chieftaincy; historical rivalries that span generations; transformations that consolidate regional systems; emotions and performances between wrestlers and fans. The dynamics of ritual organization, especially of the egitsü, a post-funeral ceremony in honour of chiefs, shuffles inter-ethnic relations. Such configurations promote alliances and oppositions that affect the formation of teams, and, consequently rearranges the fans at each event. This article gives greater visibility to the relations between playing and cheering, mediated by the faculty of looking, in the celebrations of victories, indicating the transformations unleashed in the relational universe of the peoples of the region. Fundamental positions for ritual combats, the nginiko ("onlookers"), bring to light new angles to deal with the complexity of relationships in the context of the so-called pax xinguana. 


\section{Apresentação do problema}

A luta corporal kindene $e^{2}$ uma prática esportiva dos povos alto-xinguanos. Constitui-se de conjunto de conhecimentos tradicionais, mitológicos e rituais que dão forma e conteúdo a um modelo primordial de relacionamento interétnico, destacando sobremaneira as principais características atribuídas aos povos da região, a chamada pax xinguana. Ela se caracteriza pelo "amansamento" ou "xinguanização" dos multifacetados povos que passam a compor esse complexo regional, por vezes, sob uma mesma designação étnica vinda do exterior (Menezes Bastos, 1984, 1995). Também, pela expansão do comportamento típico da calma e generosidade, da formalidade ritual, da dieta antivenatória e anticanibal, as lutas rituais são expressões decisivas dos processos descritos como "virar

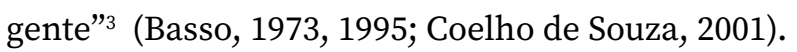

Uma apreciação detalhada sobre a luta deve ser composta por uma variedade de segmentos interligados, passíveis de serem destotalizados apenas nesse plano analítico: o ensinamento mitológico, que diferencia os povos que lutam daqueles que guerreiam (Agostinho, 1974a; Galvão, 1979; Fausto, 1999); a linguagem ritual como idioma preferencial perante a guerra nesse complexo multiétnico e multilinguístico, alargando o sistema de trocas (Gregor, 1990; Menezes Bastos, 2001); as exegeses nativas dos povos que passam a compor esse sistema regional (Menezes Bastos, 1989; Basso, 1993); e a corporalidade, "idioma simbólico de referência" para os estudos dos povos ameríndios (Viveiros de Castro, 1977, 1979; Seeger et al., 1979).

Pode-se, ainda, mobilizar o idioma da corporalidade para se refletir sobre outros campos menos debatidos na literatura etnológica, como os processos de esportificação das práticas, para alguns denominada de "esportividade ameríndia" (Vianna, 2008). Para além da utilização frequente do termo nas etnografias que descrevem disputas corporais indígenas como esportes, pretendemos compreender a esportificação em suas conexões com processos mais amplos de pacificação das relações. Processos históricos análogos ao que trabalharemos no contexto alto-xinguano em que um conjunto de práticas matrimoniais, comerciais, cerimoniais, atuaram decisivamente para a pacificação das relações interétnicas, tendo na luta esportificada um fenômeno definidor ${ }^{4}$.

Com toda essa suntuosidade, a luta contra o outro é realizada em determinadas situações, especialmente, em momentos cerimoniais. Tais ocasiões apresentam diferentes emoções envolvidas, apesar das dinâmicas dos combates propriamente serem semelhantes. No egitsü, ritual pós-funerário em homenagem aos chefes falecidos, mais conhecido como Quarup, tensões e ambiguidades afloram, disputas e rivalidades são resolvidas - ou potencializadas - durante os confrontos (Guerreiro, 2012, 2015; Costa, 2013). Nas cerimônias de troca uluki, menores em proporções e participantes, é enfatizado seu caráter mais amistoso (Novo, 2020). Nos tiponhü, rituais de passagem que celebram a entrada dos jovens chefes no período de reclusão pubertária (Barcelos Neto, 2005), a luta é realizada após a furação das orelhas dos neófitos que adentram nessa etapa de fabricação corporal
1 Expresso meus agradecimentos às duas pareceristas anônimas e à equipe editorial da Anuário Antropológico, em especial para a professora Kelly Silva, pela leitura criteriosa, críticas e sugestões que ajudaram no desenvolvimento do texto. Agradeço também ao professor Luiz Costa por realizar a tradução da versão para o inglês.

2 Palavras e expressões nativas estão grafadas em itálico. As pesquisas que servem de base para este artigo foram realizadas junto aos Kalapalo da aldeia Tanguro para confecção de tese de doutorado (Costa, 2013). Seguindo os padrões metodológicos da pesquisa etnográfica em antropologia, passei aproximadamente 14 meses em campo, divididos em cinco estadias. Tal estratégia possibilitou acompanhar oito edições do egitsü, momento maior de disputa na luta, tema de referência para a pesquisa tanto no plano conceitual, como empírico. Kindene é o nome da prática mais conhecida por huka-huka, termo usado principalmente no "português de contato".

Diversos autores já levantaram semelhanças aos marcadores da alteridade nas línguas da região. Para os Kalapalo, kuge hekugu (gente de verdade) é um tipo de autorreferência, saindo do otomo, algo traduzível por "o pessoal de", denotando proximidades familiares, geralmente relacionada a algum território. Kuge (gente), seriam aqueles com quem se estabelecem relações interétnicas, seja através dos rituais, das trocas comerciais, matrimoniais, enfim, os que dividem um mesmo modo de vida, com características como a dieta à base de peixe, 0 pacifismo, as aldeias circulares, a evitação entre afins. Ngikogo seriam os "outros diferentes", populações indígenas com contatos esporádicos, povos "feios, bravos", a imagem da alteridade distante, perigosa. 
e são apresentados na linha sucessória da chefia. Por fim, nos iamurikuma, relacionados com as flautas sagradas e a marcante presença das mulheres, transcorrem as lutas femininas (Mello, 2005).

Entretanto, não é somente nos rituais que ocorrem as disputas, de onde insistimos em seu caráter de modelo de relacionamento interétnico. Não se luta contra coaldeões, a não ser em treinamentos, momentos em que se almeja o aperfeiçoamento das técnicas, ou em tom de brincadeira, marcados pela ludicidade e descontração que caracteriza, por exemplo, os banhos no rio ao fim do dia.

A luta de verdade (kindene hekugu) é primordialmente contra o outro, por isso é relativamente comum que, na chegada de um visitante a determinada aldeia, ele se posicione no pátio central e se defronte contra todos os lutadores locais, ficando malvisto se não aguentar os combates. Disputas também são realizadas quando se selam alianças rituais, isto é, mesmos povos que se juntam para um evento se confrontam dias antes, quando da chegada dos aliados à aldeia anfitriã. Esses combates são seguidos das apresentações das flautas atanga, instrumento dos lutadores campeões, e que selam a aliança ritual. Com quem se toca flauta junto, aos pares, não se luta contra, ao menos não naquele egitsü, em homenagem àqueles chefes com os quais são relacionados via parentesco.

Percebe-se como a luta é presença constante, modo cardinal de lidar com a alteridade, seja no diversificado sistema cerimonial regional, nas visitas informais a aldeias estrangeiras ou mesmo para a consolidação de alianças organizacionais. Portanto, por delimitações metodológicas, nosso foco será nos egitsü, auge não apenas dos combates, mas poderíamos dizer do próprio universo alto-xinguano. Ocasião única em que se encontram num mesmo espaço/tempo gente dos nove povos que compõem esse complexo regional. É através da descrição e análise da luta no egitsü que atingiremos os referenciais teóricos citados, da mitologia ao rito, do relacionamento interétnico ao desenvolvimento histórico, da guerra à pacificação. Em suma, um regime político esportificado de enfrentamento da alteridade, que conecta lutadores e torcedores em performances de habilidades e oposições.

Para tanto, realiza-se uma breve contextualização da região e de seu principal ritual e ápice de disputa da kindene, o egitsü. Inscrevo tais práticas em regimes de alianças e rivalidades, instaurados via o parentesco entre os chefes e os homenageados, nos quais o olhar e o se fazer ver são estruturantes. Nessas relações, a feitiçaria é também fundamental. A organização ritual configura times de luta variáveis a cada edição: anfitriões mais aliados versus convidados, destacando a relação entre chefia e exibição pública de performances.

Num segundo momento, passaremos pelas transformações das relações entre os povos que participam desse complexo regional. Partindo de uma literatura mais antiga, demonstro como as refregas do passado, apesar de associar lutadores e torcedores, eram vivenciadas em clima de permanente instabilidade, numa linha tênue entre o inimigo e/ou adversário, num momento em que guerra e ritual eram coexistentes. Por conta disso, é frequente nesta literatura a ênfase no silêncio dos espectadores e no controle das emoções envolvidas, sob risco de exaltar animosidades. Após a demarcação, e a despeito da ambiguidade do outro permanecer,
Por fim, os kagaiha, "brancos". Saber lutar é pré-requisito para ser "gente".

4 Para Elias (1992), que trata das múltiplas facetas do processo civilizatório ocidental, esportificação remete a transformação e mudança, não é algo, mas processa a mudança de algo: "mostra claramente como o esporte é um fenômeno estratégico para o entendimento histórico de longa duração denominado por ele de processo de civilização" (Leite Lopes, 1995, p. 141). Paralelamente, veremos como as práticas corporais alto-xinguanas estão inseridas em conjuntos mais amplos de redes de relacionamentos que visam a diminuição de conflitos bélicos em nome de disputas. Isso numa região marcada pelo "idioma da corporalidade". Nossa proposta é focar na kindene como modelo relacional interétnico, parte da consolidação da pax xinguana, em consonância com demais práticas já destacadas (comerciais, matrimoniais, cerimoniais). 
autores enfatizam como o abandono das práticas guerreiras, em favor de um modelo referendado nas trocas, acaba por promover a chamada pax xinguana.

Por fim, ressaltar como as disputas atuais são organizadas de modo a convocar a participação torcedora, de onde apresentaremos os nginiko (olhadores), aqueles que fazem via a faculdade do olhar a mediação entre lutadores e torcedores, produzindo e extrapolando as comemorações dos resultados dos combates. Este será o tema da terceira seção e principal contribuição deste artigo ao campo de debate sobre a kindene.

Deste modo, a ênfase no olhar pretende uma dupla perspectiva etnográfica. Primeiramente, destaca a importância conferida à visibilidade dos futuros chefes nos momentos rituais por meio da "substituição e exibição pública" (Guerreiro, 2012). Ao mesmo tempo, chamo atenção dos leitores àqueles que serão apresentados como "olhadores", posições de destaque na organização ritual, ocupadas por grandes mestres e campeões do passado, buscando uma conexão entre a sensibilidade do olhar e as formas do jogar e torcer, o modelo das relações olhar/jogar/ torcer (Toledo, 2019).

\section{Chefia/Feitiçaria, Alianças/Rivalidades: a luta no egitsü}

O Alto Xingu é geralmente descrito pelas relações entre nove povos falantes de três troncos linguísticos: Kalapalo, Kuikuro, Matipu e Nahukua (karib); Wauja, Mehinaku, Yawalapiti (aruak); Kamayurá, Aweti (tupi). Quando da consolidação dos limites do Parque Indígena do Xingu ${ }^{5}$, esses povos se concentravam cada um em apenas uma aldeia, diferente dos dias de hoje em que se multiplicaram, muitas delas, formadas por famílias de diferentes povos, a ideia de tetsualü (Mehinaku, 2010), que tão bem descreve a "mistura”, o “colorido", entre os povos da região.

Essa expansão no número de aldeias atenta para tema fundamental: a feitiçaria como motor da política, tanto no plano interno, faccional, como regional. Esse duplo movimento de fragmentação territorial e associação ritual foi trabalhado por Guerreiro (2012) através da constituição da chefia Kalapalo e seu ritual mortuário. O chefe seria como um "superpai" para seu povo, atestando a consanguinidade como marca da sociabilidade local, o "devir vegetal”, ao passo que ele - chefe - exerceria através de seus discursos rituais uma "função-Onça" perante os outros, a afinidade como projeção da socialidade regional, a "predação" (cf. Fausto, 2017). Ser o "dono do morto" para dentro e o "dono da morte" para fora. A expansão desse processo teria como resultado, no plano sincrônico, a separação entre aldeias e conglomerados regionais, ao passo que, na diacronia, resultaria na separação dos povos.

Já para Barcelos Neto, a relação entre chefia e feitiçaria seria a ignição para outras formas de lidar com a alteridade, que poderia engendrar tanto a quebra do prestígio do chefe, ocasionando a dispersão de seu povo e recorrente fragmentação territorial, como a ampliação de sua influência, de seu raio de ação, incrementando sua própria aldeia. Essa relação entre chefia e feitiçaria se desenvolveria através dos rituais Wauja, voltados para a confecção de máscaras e as capacidades
5 Para detalhes do Decreto Lei n 50.455 de 14 de abril de 1961, assinado pelo Presidente Jânio Quadros: Lea (1997, p. 73) e Menezes (2000, p. 299). Atualmente, a denominação é Terra Indígena do Xingu (TIX). 
dos chefes em aglutinar gente para realizar essas festas ${ }^{6}$. O duplo efeito político da feitiçaria, eliminar ou exilar os adversários de um chefe, ou se voltar contra este para comprometer seu prestígio (Barcelos Neto, 2006).

Há que se destacar o caráter estrutural dessa relação entre chefia e feitiçaria. $\mathrm{Na}$ ausência de conflitos bélicos, considera-se que toda morte é causada pela feitiçaria e todo grande chefe morto deve receber um egitsü em sua homenagem (Vanzolini, 2010). Isso acaba por acionar um ciclo: mais chefes mortos, mais rituais interétnicos, maiores possibilidades de ser alvo da feitiçaria, tanto no plano local, como regional - altamente interdependentes (Franchetto; Heckenberger, 2001).

Passamos por este controverso tema para manter a proposta de trabalhar a luta a partir do egitsü’. A relação entre fragmentação das aldeias e alianças organizacionais, reflexo da oposição e associação entre chefia e feitiçaria, é a dinâmica que dirige a preparação ritual. O egitsü é um ritual pós-funerário em homenagem aos chefes falecidos, cujos parentes mais próximos são os "donos do morto" (cf. categoria "dono": Fausto, 2008; Guerreiro, 2016), a quem cabe executar inúmeros procedimentos, dentre os quais, os convites. Os "donos do morto" mais os chefes anfitriões realizam dois tipos de convites: um para os aliados, aqueles cujas famílias são relacionadas através do parentesco com o homenageado falecido; e outro para os convidados, que serão os adversários nas lutas.

Esse intricado sistema de convites foi recuperado para tratar da ideia de aliança, mas de outro ponto de vista. Esse caráter "estratégico" das alianças, debatido em autores como Cohn e Sztutman (2001), será desenvolvido nesse contexto de pacificação social, isto é, para retomar uma abordagem frequente sobre a região que demonstra a transformação da guerra em ritual, estilizada através de embates corporais: "a afirmação categórica, dos Xinguanos e seus pesquisadores, que o ritual toma o lugar da guerra" (Hugh-Jones, 2015, p. 699). Por certo, a ideia remete a Clastres, para quem a guerra indígena pressupõe aliança em outro plano:

Aliança, que não é desejada como um fim, mas apenas como um meio: o meio de atingir a empresa guerreira com os menores riscos e os menores custos... Em resumo, a realidade da aliança possibilita uma troca completa que respeita não somente aos bens e serviços, mas às relações matrimoniais (Clastres, 1980 , p. 36-37).

É na associação entre essas alianças estratégicas e rivalidades históricas que se consolidam, resumidamente, as posições eventuais a cada novo ritual, incididas diretamente na luta: os "donos"; os "aliados", relacionados aos falecidos via parentesco; e os "convidados", que serão os adversários". Desta forma, o time anfitrião e seus aliados se defrontam contra cada um dos povos convidados, sendo que os combates são realizados separadamente. Em geral, os anfitriões se aliam a mais um ou dois povos, disputando um total de cinco ou seis confrontos, dependendo da quantidade de convidados participantes. Isso faz com que os anfitriões realizem bem mais combates que seus adversários. Um campeão anfitrião pode fazer até
6 Fausto (2007, p. 30) divide os rituais alto-xinguanos em "festas para espíritos e festas para pessoas importantes". Tomaremos por sinônimos festa e ritual. Perrone-Moises (2016).

Os egitsü ocorrem na época da seca, variando entre julho e outubro. Atualmente, são realizados com pelo menos 15 dias de intervalo entre um e outro, sendo comum entre três a cinco por ano, dependendo de inúmeras condições.

8 "the categorical claim, of the Xinguano's and their researches, that the ritual takes the place of war".

9 Para melhor apreciação sobre as posições organizacionais (donos do morto, donos dos convidados, coordenadores, convidadores, aliados, convidados) e o sistema de convites, Guerreiro (2012, p. 49, 419). Aqui especificaremos a partir dos times de luta: anfitriões mais aliados versus convidados, posições cambiáveis a cada evento. 
dez lutas num único dia, ao passo que um campeão convidado irá fazer duas ou três.

A luta no egitsü é o final de todo um ciclo de atividades que poderíamos aqui, senão, mencionar as principais: ofertas de alimentos, busca e ornamentação das efígies que serão os homenageados, discursos, cantos, flautas, danças, o roubo do fogo, enfim, etapas que acontecem previamente e pelas quais apenas passaremos para manter o foco na luta ${ }^{10}$.

Geralmente num domingo pela manhã, os anfitriões e aliados se reúnem nas casas em que residiam os falecidos homenageados e na "casa das flautas", no centro da aldeia. Os adversários estão acampados nos arredores da aldeia e separados entre si. O dono do egitsü faz a convocação e os lutadores anfitriões passam a fazer uma dança característica até que se juntam defronte da casa das flautas. Então, os adversários começam a adentrar o pátio e fazem um grande círculo em torno dos anfitriões, de maneira estrondosa, com gritos e batidas de pé.

A configuração imediatamente antes do início dos combates é a seguinte: anfitriões e seus aliados ao centro e os convidados espaçados no pátio formando um semicírculo, apartados entre si. As lutas ocorrem entre os anfitriões contra cada um dos convidados, um de cada vez. Outra divisão organizacional está ligada à política, à chefia propriamente. Ocorre uma separação entre os campeões (kindotoko, lit. "donos de luta"), os "primeiros" (hotuko), futuros potenciais chefes, dos que aqui chamaremos de "lutadores comuns". Essa separação tem por objetivo dar visibilidade, apresentar os substitutos dos chefes atuais, que escolhem e determinam a ordem das apresentações ${ }^{11}$. São em torno de 10-15 embates que ocorrem um de cada vez, entre os campeões locais contra os campeões adversários, sendo seguidos das lutas dos "lutadores comuns", em que inúmeras acontecem ao mesmo tempo.

Definiremos confronto o conjunto de apresentações individuais e lutas coletivas entre os anfitriões contra cada um dos povos convidados, sendo feita nova convocação e exibição dos campeões para todos eles. Se confronto é esse bloco de lutas, combates são as refregas em si, realizadas entre dois oponentes. A luta é a mesma: devem agarrar a parte de trás da perna de seu rival, segurá-los por trás ou aplicar algum golpe de arremesso para obter a vitória. Para tanto, utilizam-se de uma variedade de técnicas e táticas - somente junto aos Kalapalo, foram registrados mais de 15 golpes diferentes - que consistem em agarrar mãos e pescoço do adversário e forçá-lo ao desequilíbrio na tentativa de atingir a parte posterior das pernas ou derrubá-1o ${ }^{12}$.

A diferença está na visualização: quanto melhor o lutador, maior a expectativa depositada nele, maiores as emoções produzidas, as comemorações pelas conquistas e decepções pelas derrotas, daí a importância do primeiro, da visibilidade na associação entre o jogar e o torcer. Os melhores lutadores, produzidos nas famílias de chefes, estão sendo apresentados como "substitutos" dos chefes atuais, que coordenam a organização ritual. São exibidos destacadamente antes mesmo de suas atuações performáticas diferenciais.
10 Além de amplamente descritas nas obras que tratam do egitsü, essas etapas podem ser visualizadas em: https:// youtu.be/VYuRFl5FJho. Este vídeo da Associação Yawalapiti Awapa sintetiza os principais acontecimentos do chamado "final" do ritual. Acesso em: 03 mar. 2021.

11 No sábado véspera dos confrontos, os chefes anfitriões e aliados se reúnem no centro da aldeia e, de maneira formal, realizam a convocação dos campeões. A ordem pré-estabelecida respeita as capacidades técnicas: quanto antes convocado, melhor é o lutador. Essa convocação é feita apenas para os campeões, que saem de suas casas e se apresentam ao centro em posição de quatro apoios, semelhante ao que acontece antes de cada confronto no dia seguinte. A ordem da convocação, negociada entre os chefes e que ajudaria a entender o caráter "estratégico" das alianças, é mantida nos combates de acordo com as possibilidades, como lesão, cansaço, feitiço.

12 A luta na mitologia ocorre no primeiro egitsü, realizado por Sol e Lua em homenagem à sua mãe quando se defrontam os animais terrestres versus os peixes. Uma série de combates terminam empatados, entre os campeões de cada time, até que duas lutas especificam as maneiras de ganhar. Não 


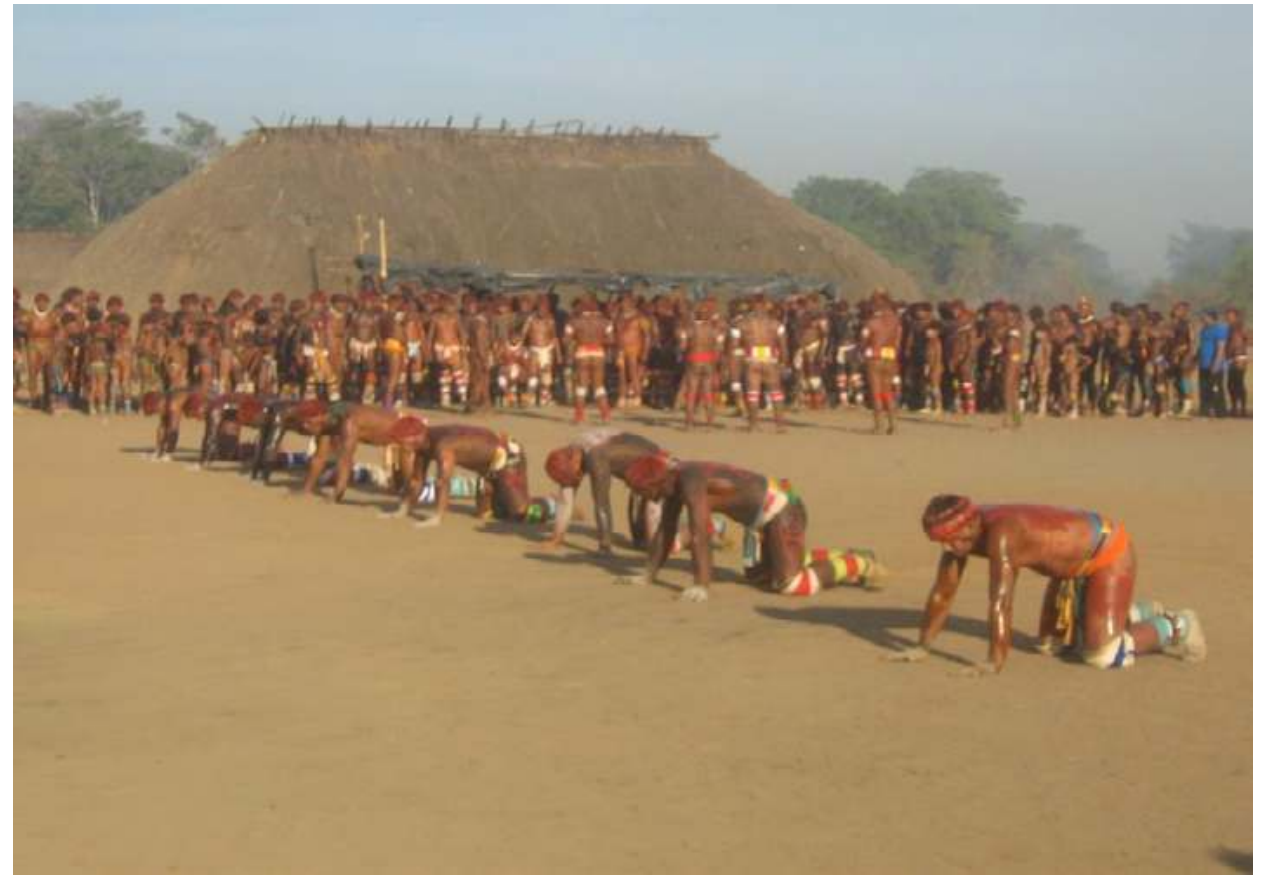

Os kindotoko são resultados de investimentos materiais e simbólicos, individuais e familiares, produzidos de maneiras semelhantes, principalmente através da reclusão ${ }^{13}$. Essas pequenas variações são colocadas à prova durante os combates, $o$ que talvez ajude a entender a alta incidência de empates. Os lutadores adversários (tikidinhü) são homólogos entre si, o que os coloca numa situação ambígua. Se o parentesco aproxima os chefes ligados a um morto comum, para quem organizam conjuntamente um ritual, a diferença entre os outros chefes deve ser instaurada de alguma maneira. A disjunção promovida por uma vitória, ainda mais uma vitória por arremesso e sua intensa comemoração com gritos uníssonos por parte da torcida, mantém a instabilidade das relações.

Neste cenário de alianças e rivalidades, ambiguidades e incertezas, a luta ritual será tomada como uma transformação da guerra, uma das características da pax xinguana. Como na famosa, e sintética, frase de um Mehinaku: "Nós não fazemos guerras; nós temos festivais para os chefes aos quais todas as aldeias vêm. Nós cantamos, dançamos, trocamos e lutamos"14 (Gregor, 1990, p. 113).

\section{Pacificação/Esportificação: transformando inimigos em adversários}

A luta é alvo de atenção desde as primeiras investigações levadas na região. Por isso mesmo, vale destacar algumas de suas transformações vividas ao longo do tempo. Von den Steinen descreve ocasião em que, "por acaso", observou confrontos entre povos distintos numa de suas viagens, isto é, estavam sendo realizados sem que fosse algo para exibir para o kagaiha que já se fazia conhecer:

Os lutadores, sempre elementos de tribus diferentes, apresentavam-se em número de dois, tendo o corpo untado, em parte com urucú amarelo-vermelho, e, em parte, com tinta preta. Acocoravam-se, erguiam do solo um punhado de areia, moviam-se ràpidamente um em tôrno do outro, sempre por acaso, os personagens são frequentes na mitologia: a Anta e o Sapo. A Anta, tida por desastrada, inapta, é arremessada contra o chão por Gafanhoto, cai sentada e por isso sua bunda é achatada. Já o Sapo, figura dúbia da alteridade na mitologia local, é um lutador forte e hábil, mas um dos heróis da narrativa, Kangasingi, que luta pelo time dos peixes, consegue ganhar dele ao tocar sua perna na parte de trás da coxa (Costa, op. cit., p. 301).

Figura 1 - Convocação e exibição dos kindotoko. No plano de fundo, os "donos do egitsü" (de costas) e os "lutadores comuns" do time anfitrião.

13 Vale notar que os processos da reclusão estabelecem uma relação dialética com o ritual também por meio das faculdades do olhar: enquanto os jovens chefes devem ser escondidos, invisibilizados dentro de casa para a fabricação corporal, seus corpos e performances são exibidos no plano regional, principalmente através das lutas (Costa, 2020).

14 "We don't make war; we have festivals for the chiefs to which all of the villages come. We sing, dance, trade, and wrestle" 
de cócoras e com os braços pendentes, mediam-se com olhares profundamente rancorosos e soltavam ameaçadores "húuhá! húuhá!" (...) Repentinamente os dois se levantavam procurando cada qual agarrar a cabeça do parceiro. Mas, apesar de todos os esforços nenhum conseguia pegar e abaixar o outro. Abraçaram-se afinal muito satisfeitos, com palmadas amigas nos ombros. Não houve luta pròpriamente dita; o final principal parecia ser o de exibir agilidade e evitar que um dos contendores fôsse subitamente agarrado na cabeça, e derrubado pelo outro. Reinava profundo silêncio entre $a$ assistência; com exceção das risadas de alguns espectadores mais críticos. (Steinen, 1940, p. 142. Itálicos nossos)

Esta descrição, apesar de sua distância temporal, narra sinteticamente o desenvolvimento do combate: a entrada dos lutadores com suas onomatopeias, as disputas por agarrar mãos e pescoço do oponente, a curta duração e a alta incidência de empates. Embora não esteja claro em que momento se deu o confronto, corrobora a comunhão entre lutador e torcida e como se transferem as emoções do plano individual para o coletivo.

Junto aos Trumai, povo de língua isolada que margeia o sistema alto-xinguano (Monod-Becquelin, 2001), Murphy e Quain (1955) apresentam ocasiões em que as lutas calhavam com atividades guerreiras, ou melhor, mesmo incursões em busca de tomada de mulheres, destruição das aldeias e assassinatos dos povos inimigos eram momentaneamente suspensas para que os confrontos pudessem ocorrer. ${ }^{15}$ Isso para assinalar as diferenças entre os povos que praticavam ou não a luta, num momento em que a ambiguidade era marca maior das relações interétnicas, enfatizando também as conexões entre competidores e torcedores:

As lutas eram especialmente frequentes durante as visitas e cerimônias intertribais. Tais ocasiões despertavam grande interesse, e o espírito competitivo aumentava, mas os espectadores têm por etiqueta não mostrar partidarismo, e os competidores fazem todo esforço para esconder a hostilidade intertribal latente. (1955, p. 91. Itálicos nossos) ${ }^{16}$.

Em caminho paralelo, Schaden traça as proximidades e diferenças entre os povos aruak, karib, tupi e jê na região, através dos processos de "aculturação" e trocas ocorridas, apontando para o fato de que a luta seria menos presente entre os jê, especialmente os Suyá. O que acabaria por afastá-los do complexo ritual que se consolidaria tempos depois devido a constantes mudanças de sítios, sendo a guerra entre os vizinhos o principal motivo. Novamente destacando a ambiguidade das relações interétnicas e o perigo engendrado nesses momentos rituais:

Importante parece ser o fato de os lutadores não se defrontarem individualmente como simples membros de suas tribos; no decorrer da luta, o competidor age, por assim dizer como delegado "oficial" de seu grupo, a ponto de a assistência se abster de tôda manifestação a favor ou contra os
15 Ainda são comuns estórias de um passado em que povos foram convidados para rituais e acabaram dizimados quando chegaram a aldeia estrangeira. Mas sempre sendo feito pelos "outros". Atualmente, o receio em não participar dessas festas é devido à feitiçaria.

16 "Wrestling matches were especially frequent during intertribal visits and ceremonials. These occasions aroused keen interest, and competitive spirits ran high, but the onlookers made it a point of etiquette to show no partisanship, and the contestants made every effort to conceal latent intertribal hostility". 
que estão medindo fôrças. É óbvio que essa ausência de «torcida» tem a função de evitar que a tensão existente entre os grupos se relaxe de forma violenta. (Schaden, 1965, p. 81. Itálicos nossos).

Atentemos nestes breves trechos recuperados para algo que evidencia as transformações sofridas por esta prática ao longo do tempo. Como afirmam os autores pioneiros, era importante a ausência das performances torcedoras para evitar que se aflorassem ímpetos e animosidades. Num tempo em que guerras e rituais eram concomitantes, variando com e contra quem praticadas, a luta era uma maneira pacífica, porém, tênue, de se lidar com a alteridade. Aqueles contra quem se lutava não se guerreava; trocavam-se mulheres e não se raptava, ofereciam-se alimentos e não destruição de aldeias, apesar das ambiguidades de tais relacionamentos.

A dubiedade do outro era, e talvez continue, um perigo a ser evitado, daí a relutância das torcidas em comemorar as vitórias de seus lutadores. Porém, uma das mais marcantes expressões da luta observada atualmente é exatamente essa transferência de emoções promovida entre lutadores e torcedores, inclusive, gerando brigas e ameaças de rompimento de relações (Costa, 2013, p. 121). Se o momento relacional atual está reificado na pacificação ritual, não quer dizer que animosidades e tensões contra o outro estejam ausentes. (cf. Schaden, idem, nota 15, p. 83).

Já no período pós-demarcação, a luta consolida as relações interétnicas e passa a dar forma ao sistema, como apontam investigadores em diferentes povos e perspectivas, ao passo que as incursões bélicas diminuem. $O$ ritual passa a ser o momento maior, a linguagem franca nesse multiétnico e multilinguístico complexo regional. Autores, como Agostinho (1974b), destacam a luta como "válvula de escape" das tensões produzidas tanto no plano interno da aldeia, nas disputas faccionais, especialmente na embaralhada formação dos Kamayurá, como no plano intertribal, sendo colocada como mecanismo de "arrefecimento das tensões".

Menezes Bastos $(1989,2001)$ associa a luta ocorrida no egitsü aos dardos disputados no jawari, ritual de origem tupi, para dizer sobre a "complementariedade" entre esses rituais no estabelecimento da "xinguanização", ou seja, o relacionamento cerimonial como marca do "amansamento" produzido pelos povos que cada vez mais abandonavam a prática guerreira em prol das competições. Ou ainda, diferente de outras regiões, no Alto Xingu a guerra deixa de ser um momento de reprodução social, de fato, improdutiva, não traz nomes, cantos, sonhos, adquirindo antes, valor negativo e feição defensiva: "No Xingu, a violência foi ritualizada e expressa na forma da luta esportiva, evento obrigatório nos rituais intertribais" (Fausto, 2007, p. 28. Itálicos nossos).

Para Viveiros de Castro, a luta estaria no centro do que foi desenvolvido como idioma simbólico, a corporalidade, e a maneira como todo o processo de fabricação do corpo, especialmente nos momentos de reclusão pubertária, eram decisivos para os desencadeamentos da luta ritual: "Quando menos, o foco mesmo das cerimônias inter-aldeias é a luta corporal entre homens - e a fabricação do 
corpo do lutador é uma das preocupações dominantes desta cultura." (Viveiros de Castro, 1977, p. 185). Além disso, Carneiro (1993, p. 427) propõe que os rituais são oportunidades de reunir e interagir com membros de outras aldeias em que são reafirmados laços sociais, cerimoniais, esportivos e econômicos, promovendo a solidariedade social.

Temos, assim, desde os processos de "aculturação", ocorridos nos contatos entre povos de distintas famílias linguísticas, avançado para a consolidação do ritual como marca do relacionamento com a alteridade, a referida transformação do inimigo em adversário, dadas as práticas esportivas realizadas entre aqueles que se consideram "gente". Este breve levantamento, importante dizer, ocorre em um tempo em que se tomava genericamente aldeia por povo, isto é, apesar das mudanças sobre quais povos fariam ou não parte desse complexo, cada aldeia era tida como um povo. No caso, a despeito do esfriamento dos contatos dos alto-xinguanos "originários" aruak/karib com os Trumai e Suyá, que não participam dos eventos atualmente, os chamados "xinguanos recentes" tupi, como os Kamayurá e Aweti, passam a fazer parte do universo ritual ${ }^{17}$.

Para nossos objetivos, esta base etnográfica, que aponta a diversidade na constituição desse complexo regional e as transformações no sentido de pacificação das relações, pode ser dividida em duas complementares: as alianças estratégicas, a formação dos times de luta, e subsequente relação entre os lutadores e torcedores. A contenda política entre os chefes se atualiza através da organização ritual, tanto para a formação dos times, como, por vezes, da não participação de algum chefe em rituais.

Tomaremos essa variedade e sua instabilidade característica associando esses dois importantes temas: o multifacetado universo cerimonial interétnico, através da formação dos times com suas alianças estratégicas e oposições históricas, e a importância do olhar na consolidação da relação entre jogar e torcer.

\section{Olhar/Jogar/Torcer: nginiko e a mediação entre lutadores e torcedores}

Uma das questões basilares dos estudos sobre jogos, do caráter lúdico de determinadas manifestações humanas a despeito do tempo e espaço, é a maneira como se transferem as emoções, êxitos e desencantos do plano individual para o coletivo, as conexões entre a prática do jogar e as performances do torcer. Essa relação entre o plano individual do jogar e o sentimento de pertença mobilizado por coletivos torcedores é atravessada pela função determinante do olhar. É desta maneira que Toledo (2019) estabelece as relações entre esses três domínios, olhar/ jogar/torcer, e suas associações no plano das emoções promovidas pelas práticas esportivas. Neste modelo, olhar é jogar, ou ainda, tensionar a dialética entre o jogar olhado e o olhar jogado através da relação entre o(s) praticante(s) e seus torcedores.

Para a elaboração desse modelo, baseado etnograficamente no desenvolvimento das chamadas práticas esportivas, uma série de autores foram levantados no entendimento deste universo que se consolida dicotomicamente: jogo/ esporte; lúdico/competitivo; equilíbrio/tensões; play/game. Estas oposições entre
17 Apesar de não ter presenciado os Aweti nos oito eventos em que participei. Quando indagava a ausência, a resposta era "Aweti não tem campeão", ou seja, a luta como a razão pela qual se convidam, ou não, os povos para participar de seus rituais de homenagem aos falecidos chefes. 
a dimensão lúdica, supostamente desinteressada e historicamente determinada pela ordem cultural pré-moderna e o aspecto competitivo das práticas esportivas, fenômeno constitutivo das sociedades burguesas, foram amplamente debatidas na literatura, desde autores como Huizinga (1993[1938]), Caillois (1988[1950]), Elias (1992), de acordo com preceitos de épocas ou objetivos analíticos:

Disso resulta, para efeitos do modelo que, todo jogar é jogo olhado. Olhar é dar coexistências às coisas, transformá-las em objetos ou objetivos. 0 modelo das relações os trata, jogadores e torcedores, como ocorrências tardias dos sentidos e metaforizações das experiências do jogar e do olhar. (Toledo, 2019, p. 44. Itálicos nossos).

Com tal constatação, voltamos para a luta cerimonial e decorrente pacificação das relações, o que foi ressaltado tanto nos discursos nativos como analíticos. Essa relação se torna mais evidente ao expressar a indissociabilidade entre olhar/jogar/ torcer. É com esse objetivo que tomaremos tal modelo através da relação entre a luta (jogar), a composição das torcidas (torcer) e a figura dos nginiko, "olhadores" (olhar). Será demonstrada etnograficamente a conexão entre esses atos durante as lutas e suas variações, a produção e transferência das emoções ligadas aos resultados dos combates.

Os nginiko não são árbitros, não determinam resultados dos embates, tampouco influenciam em seus prosseguimentos, mas promovem conexões entre quem joga e quem torce. Entre os lutadores que estão no momento efetivo da disputa e seus variados coletivos torcedores. Isso porque, devido à complexidade organizacional dos rituais, a referida relação de parentesco entre chefes e homenageados, são alterados substancialmente a cada evento ratificando rivalidades e alianças situacionais. O mesmo torcedor que vibrou com a vitória de um competidor numa luta pode torcer contra ele dali alguns dias, quando a configuração dos times e torcidas for outra. É dessa maneira que a relação entre o jogar e o torcer, mediada pelo olhar, se mostra fundamental no desenvolvimento dos combates e das relações interétnicas.

No plano dos resultados, estes não se medem através de contagens sequenciais e cumulativas, mas sim de performances diferenciais, tanto dos lutadores, que devem arremessar seus oponentes com força e sagacidade, como também dos torcedores, que devem gritar o mais alto a cada nova vitória. É aí que se mostra importante a figura do "olhador", pois, devido às diferentes formas de vitória, por arremesso ou por tocar a parte de trás da perna do oponente, a visibilidade é dificultada pela distância entre os lutadores e os coletivos torcedores formados.

São os olhadores que chamam a vitória de seus competidores quando esta não é obtida de maneira inconteste. $O$ olhar dos nginiko faz a mediação entre a atuação do competidor, que deve demonstrar técnica apurada para vencer seu oponente, com a performance torcedora, que deve gritar alto para suprimir a possibilidade de dúvida do resultado quando este não é absolutamente conseguido. Por isso mesmo, essa posição central para o desenvolvimento dos combates não pode ser 
ocupada por qualquer um. É um lugar destinado aos antigos campeões, mestres dessa arte marcial, acostumados com as técnicas e táticas, em suma, esses mediadores têm o "olhar domesticado" de um corpo e pessoa fabricados para a luta.

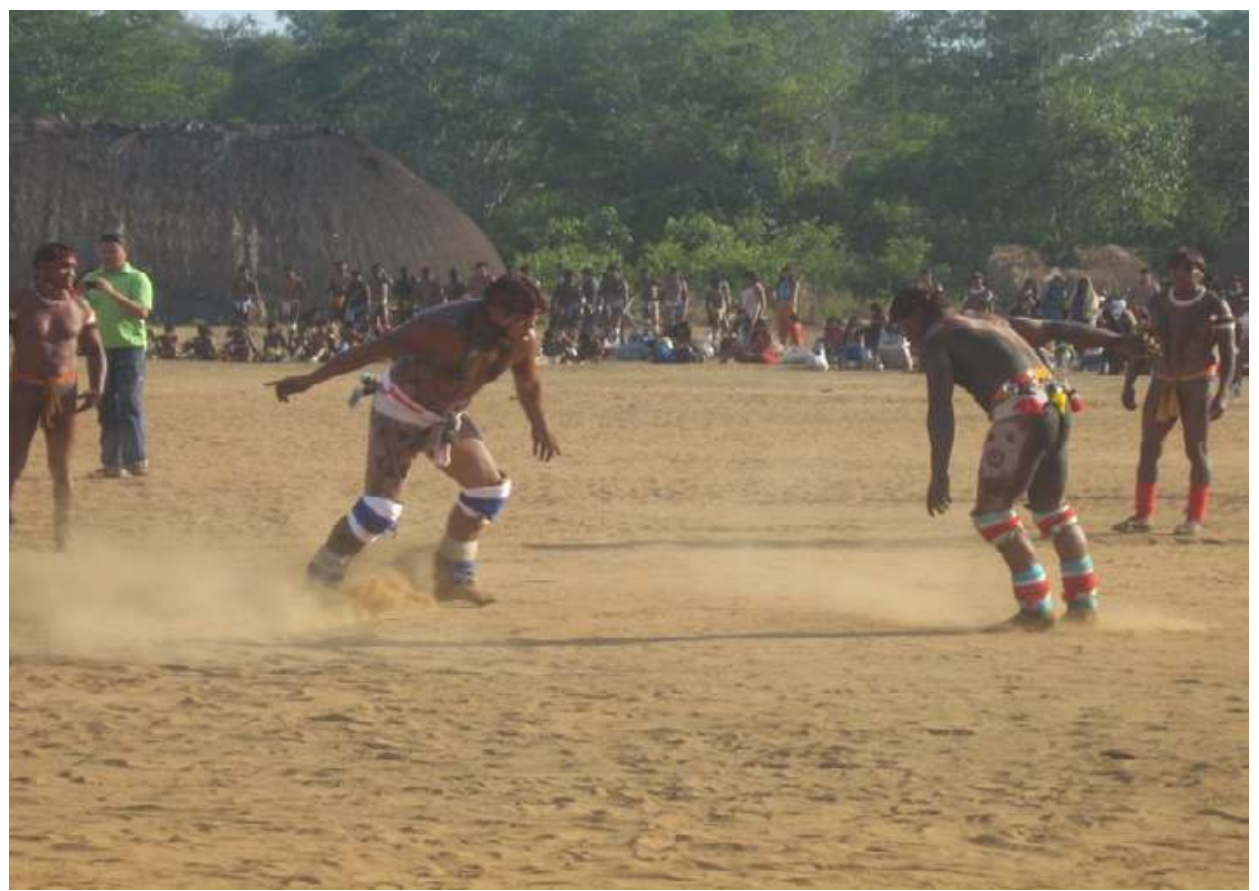

Não por acaso, diversas vezes ambas as torcidas gritam resultados diferentes. São três resultados possíveis: vitória, derrota e empate, sendo que o empate é amplamente aquele que mais acontece, por volta de $70 \%$. Sendo esses resultados possíveis no combate, no jogar, para o torcer são apenas dois: os gritos empolgados e acalorados de vitória e o grito chocho e modorrento do empate - sendo a derrota lamentada com o silêncio.

Então, olhar a vitória, principalmente aquela que deixa alguma margem para dúvida, exige extrapolar os sentidos e ser comemorada empolgadamente através dos gritos das torcidas, o que se torna mais factível nesse contexto de pacificação e maior controle das emoções envolvidas. Muitas vezes, cada torcida canta resultados diferentes para uma mesma luta: um olhador chama a vitória de seu lutador, ao que é acompanhado por sua torcida, enquanto o outro olhador também chama sua própria torcida para cantar a vitória de seu competidor. Essa suposta confusão pode ocorrer quando um chama a vitória e o outro o empate. Se os resultados deixam margens para dúvidas, a disputa jogada se transfere/transforma numa disputa torcida, mediada pela olhada do olhador.

A busca pela glória, que marca qualquer atividade lúdica, associa lutadores e torcedores, coletivos formados diferentemente a cada ritual. De fato, olhar/jogar/ torcer pode ser uma chave analítica para essa questão há tanto colocada: como se transferem os êxitos (e fracassos) do plano individual para o coletivo, do jogador para o torcedor, de onde as emoções emergem com vitalidade. Num contexto em que a atividade guerreira era presente, fazia-se necessário conter os ânimos e evitar manifestações torcedoras e animosidades. Entretanto, nesse momento em que
Figura 2 - Início de combate entre campeões, sob olhar atento dos nginiko. 
a prática é disputada ritualmente, as comemorações se intensificam e dinamizam as oposições interétnicas.

Rivais em um egitsü podem torcer por seu antigo adversário no evento seguinte, mas a torcida será a mesma, gritar a vitória ou chamar o empate. Claro que, etnograficamente, as alianças se reduzem de acordo com as possibilidades matrimoniais que enfatizam certas associações, a despeito de diminuírem em outras $^{18}$. A questão é demonstrar que, apesar dessa variedade, aqueles que fazem parte de uma mesma torcida, num evento específico, irão torcer para seu lutador, mesmo que ele não seja do mesmo povo ou aldeia que o torcedor. Essa simbiose entre lutador e torcida promove identificações imediatas, marcadas pelo tempo/ espaço ritual, que rompem os limites das aldeias, étnicos, linguísticos, estabelecendo uma aliança estratégica momentânea.

Formar grandes times, que não percam sendo anfitriões, é um dos maiores desafios para os donos dos egitsü. Então, a aliança entre os grupos relacionados aos falecidos homenageados coloca povos distintos para formarem um mesmo time de luta. E esse time vai ter entre seus hotuko apenas os melhores lutadores de cada um dos povos que formarem essa aliança, tida não como um fim, mas como meio de obter os melhores resultados. E, independente do povo ou aldeia em que resida, a torcida irá cantar sua vitória ${ }^{19}$.

Para além da demonstração etnográfica da associação entre jogar e torcer, a luta alto-xinguana apresenta uma figura mediadora que está ali exatamente para olhar, ou seja, a relação entre a prática esportiva e a prática torcedora é mediada pela prática do olhar. Olhar/Jogar/Torcer formam um contínuo variável de acordo com as relações entre donos, aliados e convidados. A produção e transferência das emoções são colocadas por todos os participantes, sejam os lutadores e seus desempenhos técnicos, os olhadores que fazem a mediação entre o jogar e o torcer, e os torcedores cujas performances conflitantes, especialmente nos combates marcados pela ambiguidade do resultado, são alvos de expectativas e disputas.

\section{Considerações finais}

O objetivo deste artigo foi associar dois modelos analíticos que se convergem quando tomados a partir do universo que envolve as disputas através das lutas. $\mathrm{O}$ primeiro diz respeito à construção social da chefia mediante práticas do "olhar", do "ser visto", "ficar conhecido", através dos rituais mortuários. É na duplicidade entre $o$ inato e o adquirido que se formam os grandes chefes, seja pela continuidade substancial e corpórea, a linhagem e a genealogia, pois, para ser chefe há que ser filho de chefes. No entanto, é preciso também fazer-se liderança por meio de atuações públicas (Guerreiro, 2012).

Desde o ritual de furação de orelhas, os jovens passam a ser exibidos regionalmente para atestar a continuidade da chefia. Furar as orelhas com fêmur de onça, sentar nos bancos, ser "conduzido pelos pulsos", ser recebido em aldeias estrangeiras, fazem parte desse vasto processo de fabricação corporal e formação da pessoa que tem por finalidade tornar o chefe conhecido (tuhitinhü). Ser um
18 O caso de como os Yawalapiti se reestruturaram através de casamentos estratégicos com chefes Kalapalo, Kuikuro, Kamayurá talvez seja o mais emblemático (Menezes Bastos, 1989; Guerreiro, 2012).

19 Como exemplo etnográfico, destacaria a aliança Kalapalo/Matipu em que, apesar de egitsü ocorrido na aldeia Matipu, apenas um lutador local fazia parte do time de campeões, os demais eram Kalapalo. Ou seja, mesmo com a aliança via parentesco, a estratégia para os confrontos é fator determinante na formação dos times, escolhidos pelos donos do egitsü. Noutro exemplo, Kalapalo/Yawalapiti juntos fizeram um time imbatível. Porém, quando adversários, seus lutadores principais, o "primeiro" de cada um, fazem uma das mais excitantes rivalidades contemporâneas - e que, um dia, já se deu entre seus pais. Os combates entre eles são momentos de grande expectativa e entusiasmo por parte dos torcedores, alguns, inclusive, com ambas as torcidas celebrando a vitória de seu competidor. Mas quando estavam no mesmo time, os torcedores Kalapalo e Yawalapiti se juntaram para celebrar suas vitórias. 
grande lutador, um campeão que se apresenta entre os primeiros, que não perde, é um dos ápices dessa construção, o "aspecto biográfico" dos chefes em formação (Barcelos Neto, 2005). O egitsü é o momento em que os chefes do passado são homenageados pelos chefes do presente, no qual apresentam seus futuros chefes aos seus rivais regionais.

Embora todos os jovens pratiquem a luta, somente aqueles que estão nas linhas sucessórias das chefias têm possibilidades concretas de se tornarem campeões, seja por conta da família, dos processos exigidos durante a reclusão, dos ensinamentos tradicionais e de suas posições rituais. Não por acaso, todos os grandes chefes atuais são considerados grandes lutadores de seus tempos, o que é reconhecido no âmbito regional.

Ademais, a centralidade do olhar, da visibilidade dos chefes que se apresentam nos combates rituais, foi considerada a partir de outra função do olhar, a saber, aquela que se estabelece entre jogar e torcer. Ao tratar dessa conexão entre jogar e torcer, mediada pelo olhar, a proposta foi pensar num conjunto de transformações que acabaram por redimensionar as relações interétnicas entre os distintos povos que se encontram na região. Num primeiro momento, em que a instabilidade das relações e a possibilidade da atividade guerreira era uma constante vivida, a relação entre as torcidas era de tal monta que sua participação era quase nula, abstendo-se de comemorações ou provocações, exatamente dada a ambiguidade que colocava frente a frente potenciais inimigos, embora estivessem a competir na modalidade de luta. Todavia, devido aos processos de transformações reconhecidos por pax xinguana, um conjunto de povos, por vezes reunindo alteridades sob o mesmo nome numa mesma aldeia apesar de suas diferenças internas, acabou por ratificar esse sistema regional.

Paulatinamente, outros povos deixaram de fazer parte da rede de convites porque, por suposição, não disporiam de lutadores campeões. Com a consolidação de quem seriam os outros a participar dos rituais regionais, as performances dos torcedores se tornaram mais ativas. É nesse sentido que destacamos as transformações do torcer atreladas ao olhar dos nginiko. Se antes a comemoração era contida, hoje ela é chamada a vir acontecer exatamente por essa figura do "olhador", muito embora, e apesar da pax xinguana, como em qualquer outro ambiente esportivo e de disputa, rivalidades possam aflorar e brigas ocorreram. Nesses contextos, é fundamental a atuação dos chefes para acalmar os ânimos.

Deste modo, as relações interétnicas desenroladas ritualmente são observadas por uma nova luz, que clareia seu dinamismo, ainda mais dado o contexto atual de profusão no número de aldeias de um mesmo povo e suas formações, expressado na ideia de tetsualü. $\mathrm{O}$ poder e prestígio dos chefes são colocados à prova a cada novo evento, sendo que a formação de um bom time de luta é um dos itens mais avaliados entre os participantes. "Alianças estratégicas" são então retomadas, não mais para as incursões guerreiras, mas para as disputas rituais em suas variabilidades características. 


\section{Referências}

AGOSTINHO, Pedro. Mitos e outras narrativas Kamayura. Salvador: Editora da UFBA, 1974a.

AGOSTINHO, Pedro. Kwarìp: mito e ritual no Alto Xingu. São Paulo: EPU/EDUSP, 1974b.

BARCELOS NETO, Aristóteles. Apapaatai: rituais de máscaras no Alto Xingu. Tese (Doutorado em Antropologia) - Universidade de São Paulo, São Paulo, 2005.

BARCELOS NETO, Aristóteles. De divinações xamânicas e acusações de feitiçaria: imagens wauja da agência letal. Mana - Estudos de Antropologia Social, n. 12, p. 285-313, 2006.

BASSO, Ellen. The Kalapalo Indians of Central Brazil. New York: Holt, Rinehart \& Winston, 1973.

BASSO, Ellen. A história na mitologia: uma experiência dos Avoengos Calapalos com Europeus. In: COELHO, V. (Org.). Karl von den Steinen: um século de antropologia no Xingu. São Paulo: EDUSP, 1993. p. 313-345.

BASSO, Ellen. The Last Cannibals: A South American Oral History. Austin: University of Texas Press, 1995.

CAILLOIS, Roger. Jogo e Sagrado. In: CAILLOIS, R. O Homem e o Sagrado. Lisboa: Edições 70, 1988 [1950].

CARNEIRO, Robert. Quarup: A Festa dos Mortos no Alto Xingu. In: COELHO, V. (Org.). Karl von den Steinen: um século de antropologia no Xingu. São Paulo: EDUSP, 1993. p. 405-429.

CLASTRES, Pierre. Arqueologia da violência: a guerra nas sociedades primitivas. In: CLASTRES, P.; GAUCHET, M.; ADLER, A.; LIZOT, P. (Orgs.). Guerra, religião, poder. Lisboa: Edições 70, 1980. p. 11-47.

COELHO DE SOUZA, Marcela. Virando gente: notas a uma história Aweti. In: B. FRANCHETTO, B.; HECKENBERGER, M. (Orgs.). Os Povos do Alto Xingu: história e cultura. Rio de Janeiro: Editora da UFRJ, 2001. p. 358-400.

COHN, Clarice; SZTUTMAN, Renato. O visível e o invisível na guerra ameríndia. Sexta Feira, n. 7, p. A43-A54, 2003.

COSTA, Carlos. Kindene hekugu. Uma etnografia da luta e dos lutadores no Alto Xingu. Tese (Doutorado em Antropologia) - Universidade Federal de São Carlos, São Carlos, 2013.

COSTA, Carlos. Política da reclusão: chefia e fabricação de corpos no Alto Xingu. $R @ U$, v. 12, n. 1, p. 145-172, 2020. Disponível em: https://doi.org/10.52426/rau.v12i1.335. Acesso em: 20 abr. 2021.

ELIAS, Norbert.; DUNNING, Erik. A busca da excitação. Lisboa: Diffel. 1992.

FAUSTO, Carlos. Da Inimizade: forma e simbolismo da guerra indígena. In: NOVAES, A. (Org.). A Outra Margem do Ocidente. São Paulo: Cia. das Letras, 1999. p. 251-282.

FAUSTO, Carlos. Entre o Passado e o Presente: mil anos de história indígena no Alto Xingu. Revista de Estudos e Pesquisas, n. 2, p. 9-52, 2007.

FAUSTO, Carlos. Donos demais: maestria e domínio na Amazônia. Mana - Estudos de Antropologia Social. v. 14, n. 2, 2008. p. 329-366.

FAUSTO, Carlos. Chefe Jaguar, Chefe Árvore: afinidade, ancestralidade e memória no 
Alto Xingu. Mana - Estudos de Antropologia Social. v. 23, n. 3, p. 653-676, 2017.

FRANCHETTO, Bruna; HECKENBERGER, Michael (Orgs.). Os Povos do Alto Xingu: história e cultura. Rio de Janeiro: EDUFRJ, 2001.

GALVÃO, Eduardo. O uso do propulsor entre as tribos do Alto Xingu. In: Encontros de Sociedades: índios e brancos no Brasil. Rio de Janeiro: Paz e Terra, 1979. p. 39-56.

GREGOR, Thomas. Uneasy Peace: Intertribal Relations in Brazil's Upper Xingu. In: HAAS, J. (Org.). The Anthropology of War. Cambridge: Cambridge University Press, 1990. p. 105-124.

GUERREIRO, Antonio. Ancestrais e suas sombras: Uma etnografia da chefia kalapalo e seu ritual mortuário. Tese (Doutorado em Antropologia) - Universidade de Brasília, Brasília, 2012.

GUERREIRO, Antonio. Quarup: transformações do ritual e da política no alto Xingu. Mana - Estudos de Antropologia Social, n. 21, p. 377-406, 2015.

GUERREIRO, Antonio. Do que é feita uma sociedade regional? Lugares, donos e nomes no Alto Xingu. Ilha - Revista de Antropologia, n. 18, p. 23-55, 2016.

HUGH-JONES, Stephen; GUERREIRO, Antonio; ANDRELLO, Geraldo. Space-time Transformations in the Upper Xingu and Upper Rio Negro. Sociologia \& Antropologia, n. 5, p. 699-723, 2015.

HUIZINGA, Joan. Homo Ludens. São Paulo: Perspectiva, 1993.

LEA, Vanessa Rosemary: Parque Indígena do Xingu: Laudo antropológico. Campinas: Universidade Estadual de Campinas, 1997.

LEITE LOPES, José. Esporte, emoção e conflito social. Mana - Estudos de Antropologia Social, n. 1, p. 141-166, 1995.

MEHINAKU, Mutua. Tetsualü: pluralismo de línguas e pessoas no Alto Xingu. Dissertação (Mestrado em Antropologia Social) - Museu Nacional, Universidade Federal do Rio de Janeiro, Rio de Janeiro, 2010.

MELLO, Maria. lamurikuma: música, mito e ritual entre os Wauja do Alto Xingu. Tese (Doutorado em Antropologia Social) - Universidade Federal de Santa Catarina, Florianópolis, 2005.

MENEZES BASTOS, Rafael. O "payemeramaraka” kamayurá: uma contribuição à etnografia do xamanismo no Alto Xingu. Revista de Antropologia, n. 27-28, p. 139-177, 2018.

MENEZES BASTOS, Rafael. Exegeses yawalapití e kamayurá da criação do Parque Indígena do Xingu e a invenção da saga dos irmãos Villas Boas. Revista de Antropologia, n. 30/31/32, p. 391-426, 1989.

MENEZES BASTOS, Rafael. Indagação sobre os kamayurá, o alto-xingu e outros nomes e coisas: uma etnologia da sociedade Xinguara. Anuário Antropológico, n. 94, p. 227269, 1995.

MENEZES BASTOS, Rafael. Ritual, História e Política no Alto Xingu: Observações a partir dos Kamayurá e do Estudo da Festa da Jaguatirica (Jawari). In: FRANCHETTO, B.; HECKENBERGER, M. (Orgs.). Os Povos do Alto Xingu: história e cultura. Rio de Janeiro: Editora da UFRJ, 2001. p. 335-357.

MENEZES, Maria. Parque Indígena do Xingu: a construção de um território estatal. Campinas: Editora da Unicamp; Imprensa Oficial, 2000.

MONOD-BECQUELIN, Aurore. Histórias trumais. In: FRANCHETTO, B.; HECKENBERGER, 
M. (Orgs.). Os Povos do Alto Xingu: história e cultura. Rio de Janeiro: Editora da UFRJ, 2001. p. 401-443.

MURPHY, Robert F.; QUAIN, Buell. The Trumaí Indians. Monographs of the American Ethnological Society, XXIV, New York, v. xii, n. 108, p. in-8, 1955.

NOVO, Marina; GUERREIRO, Antonio. Exchange, Friendship and Regional Relations in the Upper Xingu. Vibrant: Virtual Brazilian Anthropology, n. 17, p. e17354. Epub August 07, 2020. Disponível em: https://doi.org/10.1590/1809-43412020v17a354. Acesso em: 10 abr. 2021.

PERRONE-MOISÉS, Beatriz. Festa e Guerra. Tese (Livre-docência) - Universidade de São Paulo, São Paulo, 2016.

SCHADEN, E. Três Exemplos. Revista de Antropologia, n. 13, p. 65-152, 1965.

SEEGER, Anthony; DAMATTA, Roberto; VIVEIROS DE CASTRO, Eduardo. A Construção da pessoa nas sociedades indígenas brasileiras. Boletim do Museu Nacional, n. 32, p. 2-19. 1979.

STEINEN, Karl. Entre os Aborígines do Brasil Central. Revista do Arquivo Municipal, separata: XXXIV e LVIII, 1940.

TOLEDO, Luiz. Torcer: Perspectivas analíticas em Antropologia das práticas esportivas. Tese (Livre-docência) - Universidade Federal de São Carlos, São Carlos, 2019.

VANZOLINI, Marina. A flecha do ciúme: o parentesco e seu avesso segundo os Aweti do Alto Xingu. Tese de Doutorado, Rio de Janeiro: Museu Nacional, 2010.

VIANNA, Fernando. Boleiros do cerrado: Índios Xavantes e o futebol. São Paulo: Annablume; FAPESP; ISA, 2008.

VIVEIROS DE CASTRO, Eduardo. A fabricação do corpo na sociedade xinguana. Boletim do Museu Nacional, n. 32, p. 40-49, 1979.

VIVEIROS DE CASTRO, Eduardo. Indivíduo e Sociedade no Alto Xingu: os Yawalapíti. Dissertação (Mestrado em Antropologia Social) - Museu Nacional, Universidade Federal do Rio de Janeiro, Rio de Janeiro, 1977. 